\title{
FUZZY BELIEF STRUCTURE BASED VIKOR METHOD: AN APPLICATION FOR RANKING DELAY CAUSES OF TEHRAN METRO SYSTEM BY FMEA CRITERIA
}

\author{
Seyed Hossein Razavi Hajiagha ${ }^{1}$, Shide Sadat Hashemi ${ }^{2}$, \\ Yousef Mohammadi ${ }^{3}$, Edmundas Kazimieras Zavadskas ${ }^{4}$ \\ ${ }^{1,3}$ Dept of Management, Khatam Institute of Higher Education, Tehran, Iran \\ ${ }^{2}$ Saramadan Andisheh Avina Co., Tehran, Iran \\ ${ }^{4}$ Dept of Construction Technology and Management, \\ Vilnius Gediminas Technical University, Vilnius, Lithuania
}

Submitted 31 August 2015; resubmitted 29 November 2015; accepted 29 November 2015

\begin{abstract}
Public transport is a critical part of civilization in this decade. The amount of money invested and the criticality of transferring people in an acceptable time and without any conflict made it a challenging problem for managers, especially in metropolises. Absolutely, making effective decisions in this area requires considering different aspects. Waiting time is a key criterion in apprising quality of public transport. In this paper, a real world case study of ranking causes of delay in Tehran (Iran) metro system is solved by developing multi attribute group decision-making VIšeKriterijumska Optimizacija I KOmpromisno Rešenje (in Serbian, VIKOR) method under uncertainty, where this uncertainty is captured by Fuzzy Belief Structures (FBS). The obtained results are then compared with a previously proposed Technique for Order of Preference by Similarity to Ideal Solution (TOPSIS) method with FBSs. The results show that human related issues, along with the problems related to line and transportation system are the most important causes of delay. The obtained results of the problem seem acceptable for decision makers.
\end{abstract}

Keywords: group decision-making; VIKOR; fuzzy belief structure; center of gravity; failure mode and effect analysis.

\section{Introduction}

Finding an ideal decision is the pursuit of many scholars and practitioners in different fields (Tzeng, Huang 2011). Multiple Criteria Decision-Making (MCDM) is a field of operations research, which deals with evaluating and choosing the best alternative based on several criteria. Yoon and Hwang (1995) classified MCDM problems into two main categories: Multiple Attribute DecisionMaking (MADM) and Multiple Objective DecisionMaking (MODM), the former applies in evaluation type problems while the latter is suitable for design type problems (Simon (1977) classified decision problems into selection and design problems).

The aim of MCDM methods is to provide a logical and scientific framework of dealing with risky decisions. One of the main challenges of 21 st century is urbanization growth (Martine 2005). As stated by UN, today $54 \%$ of the world's population lives in urban areas (UN 2015). Considering this growing urbanization phenomena, transport plays a crucial role in urban management
(UN 2010). As Bainster (1996), and Gifford and Steg (2007) believed, transport holds major economic and social importance in improving expected standards of consumption and quality of life.

Considering the above challenges, transportation system is one of the implicational areas of MADM (Bagočius et al. 2014; Elevli 2014; Šateikienè et al. 2015). An MADM problem can be defined as follow (Zimmerman 1987): Suppose that we have a nonempty and finite set of decision alternatives, that their desirability will be judged according to a finite set of goals, attributes or criteria. The aim of MADM is to determine an optimal alternative having the highest degree of desirability in respect to all relevant goals.

The real world decision-making process is a common problem for employing the uncertainty phenomena. In fact, the required knowledge to formalize a decision-making problem are usually subjected to uncertainty. Dubois and Prade (1982), and Klir (1987) introduced ambiguity and vagueness as two types of uncertainty in

Corresponding author: Seyed Hossein Razavi Hajiagha

E-mail: s.hossein.r@gmail.com 
real-world problems. While ambiguity refers to unspecific choice between alternatives, vagueness deals with situations where there are not any sharp boundaries among some domain of interest (Inuiguchi et al. 2000).

This undeniable uncertainty is widely known and accepted in decision-making, especially - in MADM problems. Presence and acceptance of uncertainty requires a formal framework to be analyzed. Fuzzy set theory, introduced by Zadeh (1965), is one of the common frameworks in handling uncertainties (Liu, Lin 2006). Bellman and Zadeh (1970) initially applied the concept of fuzzy sets in decision-making problems. Fuzzy sets assign a membership value to each elements of a set. In ordinal fuzzy sets, this membership values are exact numbers. Some scholars criticized the ordinal fuzzy sets due to crispness of its membership values (GrattanGuinness 1976). Therefore, some extensions are given to the concept of membership functions or values.

Zadeh (1975) introduced type-2 fuzzy sets where membership function itself is a fuzzy set. As an extension, interval type-2 fuzzy sets considered membership functions as closed intervals (Liang, Mendel 2000). Simplicity of operations over intervals caused more interesting about application of interval type-2 fuzzy sets in MADM. Wang et al. (2012) have found the interval type-2 fuzzy sets a very useful mean to depict the information in decision-making process. They used it for a group decision-making problem in order to calculate the attributes weights and aggregated decision matrix. Chen (2013) used the interval type-2 trapezoidal fuzzy numbers to determine the alternatives ratings and the importance of various criteria. Baležentis and Zeng (2013) extended the MULTIMOORA method based upon fuzzy type- 2 sets and generalized interval-valued trapezoidal fuzzy numbers. This paper was proposed to aggregate the group decision-making in human resource management. The application of type-2 fuzzy numbers is illustrated in Maldonado et al. (2014), which proposed a design of multi objective genetic optimization problem.

Atanassov (1986) extended the ordinal fuzzy sets by attending a non-membership value $v$ beyond the classic membership value $\mu$, and called the corresponding set as Intuitionistic Fuzzy Set (IFS). In a classic fuzzy set $v=1-\mu$, while in an IFS, $v+\mu \leq 1$. In an ordinal IFS, the $\mu$ and $v$ values are determined as crisp numbers. Latter, Atanassov and Gargov (1989) developed IFS to Interval-Valued Intuitionistic Fuzzy Sets (IVIFSs) where membership and non-membership degrees are expressed as closed intervals. There is a planetary of researches done over extending MADM techniques under IFS and IVIFS environments (Zhou et al. 2013; Razavi Hajiagha et al. 2015; Zavadskas et al. 2015; Tan et al. 2014; Chen 2015; Hashemi et al. 2016).

Fuzzy Belief Structure (FBS) is another extension of ordinal fuzzy sets. Initially, the Belief Structure (BS) introduced by Yang and Singh (1994), and Yang and Sen (1994) as an evidential reasoning approach for solving MADM problems. In a FBS model, the linguistic variables of evaluation grades are considered as crisp values.
Yang et al. (2006) introduced the FBS where evaluation grades are expressed as fuzzy numbers. In fact, an FBS is a combination of fuzzy set theory and the evidence combination rule of the Dempster-Shafer theory and therefore is a powerful way of dealing with uncertainty. Jiang et al. (2011) applied the FBS model to extend the TOPSIS method for group decision-making. Vahdani et al. (2014) also applied the above TOPSIS and FBS method in the Failure Mode and Effect Analysis (FMEA) for ranking the risk causes.

The aim of this paper is to propose an extension of VIKOR method under FBS. VIKOR method is a compromise based method for ranking alternatives (Opricovic 1998). This method is applied for MADM problems with irrelevant and conflicting attributes (Opricovic, Tzeng 2004). As the founder of VIKOR method, Opricovic extended the fuzzy VIKOR method and employed it in some applications (Opricovic 2007, 2011). Vahdani et al. (2010) proposed the interval type-2 VIKOR method (they applied the interval-valued fuzzy sets with a similar definition of interval type-2 fuzzy sets). The method is also developed in intuitionistic fuzzy (Devi 2011) and interval valued intuitionistic fuzzy (Park et al. 2011) environments. The idea of VIKOR method is also extended to solve multi-objective linear programming problems (Razavi Hajiagha et al. 2014). In this paper, it is supposed that a group of experts participate in decision-making process, who expresses their evaluations in decision matrix based on FBS models, i.e. they determine their belief degrees' regard to fuzzy evaluation grades of each alternatives with respect to each criteria. Considering the advantages of FBS in modeling data uncertainty by aggregating fuzzy evaluation grades and belief degrees and combining these advantages with the VIKOR method's advantage in determining a compromise solution of a decision-making problem could have made the FBS-VIKOR method as an appealing method of solving Multiple Attribute Group Decision-Making (MAGDM) problems.

The rest of paper is organized as follows. The VIKOR method is briefly introduced in Section 1. Then, the required concepts of FBS models are overviewed in Section 2. The proposed method of VIKOR under FBSs is explained in Section 3. A real world case study is then solved by using the proposed method in Section 4. Finally, the paper is concluded.

\section{VIKOR}

A decision-making problem can be formulated in the form of a decision matrix consist of the following elements (Yu 1990):

- the set of alternatives $A=\left\{A_{1}, A_{2}, \ldots, A_{m}\right\}$;

- the set of criteria $X=\left\{X_{1}, X_{2}, \ldots, X_{n}\right\}$;

- the outcome or decision matrix $D=\left[x_{i j}\right]$, which element $x_{i j}$ represents performance of alternative $A_{i}$ based on the criterion $X_{j}$, for each $i=1,2, \ldots$, $m$ and $j=1,2, \ldots, n$;

- the vector $W=\left\{w_{1}, w_{2}, \ldots, w_{n}\right\}$, where $w_{j} \geq 0, j=$ $1,2, \ldots, n$ illustrates the weight or importance of criterion $X_{j}$. 
An MCDM method to rank a set of alternatives based on conflicting criteria so-called VIKOR is introduced to be employed in practical problems. This method is based on closeness to the Ideal solution. Presume a set of $m$ alternatives and $n$ criteria, where the rating of each alternative $A_{i}$ against to a criterion $X_{j}$ is denoted as $f_{i j}$. This method includes the following steps:

Step 1. Determine the best $f_{i}^{+}$and worst $f_{i}^{-}$rating for all criteria as follow:

$$
\begin{aligned}
& f_{j}^{+}=\max _{i} f_{i j} ; \\
& f_{j}^{-}=\min _{i} f_{i j} .
\end{aligned}
$$

In this regard, the ideal and anti-ideal candidates are respectively as $\left(f_{1}^{+}, f_{2}^{+}, \ldots, f_{n}^{+}\right)$and $\left(f_{1}^{-}, f_{2}^{-}, \ldots, f_{n}^{-}\right)$.

Step 2. Calculate the average $S_{i} \in[0,1]$ and the worst group $R_{i} \in[0,1]$ scores for the alternative $A_{i}$ :

$$
\begin{aligned}
& S_{i}=\sum_{j=1}^{n} w_{j} \frac{\left(f_{j}^{+}-f_{i j}\right)}{\left(f_{j}^{+}-f_{j}^{-}\right)} \\
& R_{i}=\max _{j}\left(w_{j} \frac{\left(f_{j}^{+}-f_{i j}\right)}{\left(f_{j}^{+}-f_{j}^{-}\right)}\right),
\end{aligned}
$$

where: $w_{j}, j=1,2, \ldots, n$ indicates the relative importance weights of the criterion $j$, which experts have determined.

Step 3. Calculate the $Q_{i}$ for $i=1,2, \ldots, m$ as:

$$
Q_{i}=v \frac{\left(S_{i}-S^{+}\right)}{\left(S^{-}-S^{+}\right)}+(1-v) \frac{\left(R_{i}-R^{+}\right)}{\left(R^{-}-R^{+}\right)},
$$

where:

$$
\begin{aligned}
& S^{+}=\min _{i} S_{i} \\
& S^{-}=\max _{i} S_{i} \\
& R^{+}=\min _{i} R_{i} \\
& R^{-}=\max _{i} R_{i} .
\end{aligned}
$$

Here $v$ indicates the weight of maximum group utility. It can be determined as:

$$
\begin{aligned}
& -v \succ 0.5 \text { - selected by majority; } \\
& -v=0.5 \text { - consensus; } \\
& -v \prec 0.5 \text { - veto. }
\end{aligned}
$$

Step 4. Sort the $S, R$ and $Q$ values by ascending order to rank each on. There would be 3 lists of ranking illustrated as: $S_{[0]}, R_{[0]}$ and $Q_{[0]}$.

Step 5. Indicate the smallest $Q_{i}$ value related to alternative $j_{1}$ as a compromise solution if:

- $C_{1}$ - the alternative $j_{1}$ has an acceptable advantage: $Q_{[2]}-Q_{[1]} \geq D Q$, where $D Q=\frac{1}{m-1}$ and
$m-$ the number of alternatives;

- $C_{2}$ - the alternative $j_{1}$ is stable within the decision-making process - it is also the best ranked in $S_{[0]}$ or $Q_{[0]}$.

If one of these conditions is not satisfied, then the solution is as follow:
- alternative $j_{1}$ and $j_{2}$, where $Q_{j 2}=Q_{[2]}$ if $C_{2}$ is not satisfied;

- alternatives $j_{1}, j_{2}, \ldots, j_{k}$ if $C_{1}$ is not satisfied, alternative $j_{k}$ is determined by $Q_{[k]}-Q_{[1]} \prec D Q$ for maximum $k$, where $Q_{j k}=Q_{[k]}$.

\section{Fuzzy Belief Structure (FBS)}

BS is a distributed assessment scheme where belief degrees are attained to different evaluation grades. Suppose that the evaluation grade of criteria consist a standard with $N$ grades $\left\{H_{1}, H_{2}, \ldots, H_{N}\right\}$ and assume that is preferred to $H_{k+1}$. A BS for the assessment of criterion $c$ can be represented as the following distribution:

$$
S(c)=\left\{\left(H_{n}, \beta_{n}\right), n=1,2, \ldots, N\right\},
$$

where: $\beta_{n}$ is the belief degree of the grade $H_{n}$ in the evaluation, that $\beta_{n} \geq 0, n=1,2, \ldots, N$ and $\sum_{j=1}^{n} \beta_{n} \leq 1$.

Eq. (8) means that the criterion $c_{n}$ is assessed with the belief degree $\beta_{n}$ at the grade $H_{n}$. If $\sum \beta_{n}=1$, the distribution is complete and if $\sum_{j=1}^{n} \beta_{n} \leq 1 \stackrel{-i t}{j=1}$ is incomplete.

The evaluation grade $\left\{H_{1}, H_{2}, \ldots, H_{N}\right\}$ consists of crisp number in ordinal BS. However, the ambiguity and vagueness of real-world problems required evaluation grades to be represented by fuzzy numbers. In this case, the fuzzy evaluation grades deal with fuzziness or vagueness and the belief degrees handled incompleteness or ignorance.

An important concept of FBS is to measure the belief distance. Jiang et al. (2011) defined the distance between to FBS $S_{1}$ and $S_{2}$ as:

$$
\begin{aligned}
& d_{B S}\left(S_{1}, S_{2}\right)=d_{B S}\left(B_{1}, B_{2}\right)= \\
& \left(\frac{1}{2}\left(B_{1}-B_{2}\right) \tilde{S}\left(B_{1}-B_{2}\right)^{T}\right)^{1 / 2} .
\end{aligned}
$$

That $B_{1}$ and $B_{2}$ are the belief degree distributions of $S_{1}$ and $S_{2}$, respectively. Also, $\tilde{S}=\left[\tilde{s}_{i j}\right]$ represents the similarity matrix between fuzzy evaluations grades. If the utilities of each fuzzy evaluation grade are represented by trapezoidal fuzzy numbers, i.e. $U\left(H_{n}\right)=\left(u_{1}^{n}, u_{2}^{n}, u_{3}^{n}, u_{4}^{n}\right)$, $n=1,2, \ldots, N$. Then, the similarity between $H_{i}=\left(u_{1}^{i}, u_{2}^{i}, u_{3}^{i}, u_{4}^{i}\right)$ and $H_{j}=\left(u_{1}^{j}, u_{2}^{j}, u_{3}^{j}, u_{4}^{j}\right)$ is calculated as:

$$
\tilde{s}_{i j}=1-\frac{\sum_{k=1}^{4}\left|u_{k}^{i}-u_{k}^{j}\right|}{4}
$$

where: $0 \leq \tilde{s}_{i j} \leq 1$, since $u_{k}^{n} \in[0,1], k=1, \ldots, 4$. If $H_{n}$ is a triangular fuzzy number, then $u_{2}^{n}=u_{3}^{n}$ and the similarity measure is measured as the same. Jiang et al. (2011) proved that the distance measure in Eq. (9) is located between 0 and 1 , and is a symmetric measure. This measure will be used in the proposed VIKOR based on FBS model. 


\section{VIKOR Method Based on FBSs}

As discussed earlier, in this paper, the multi-attribute VIKOR method is developed when decision-making information is given based on the FBS models. At the next subsections, the fundamentals of the proposed algorithm are explained. Then, an algorithmic scheme is presented to summarize these explanations.

\subsection{Problem Definition and Data Preparation}

The considered problem is a multi-attribute group decision-making problem. Suppose that a group of $K$ decision makers, denoted by $D M_{k}, k=1,2, \ldots, K$ are gathered to evaluate a set of alternatives $A=\left\{A_{1}, A_{2}, \ldots, A_{m}\right\}$ based on a set of criteria $X=\left\{X_{1}, X_{2}, \ldots, X_{n}\right\}$. Each decision maker has a specific importance according to his/ her role in decision-making process. Suppose that decision makers importance are determined in the form of a vector $W^{D}=\left\{w^{1}, w^{2}, \ldots, w^{K}\right\}$. In addition, the criteria weight vector $W=\left\{w_{1}, w_{2}, \ldots, w_{n}\right\}$ can be determined using methods like simple rating or group Analytic Hierarchy Process (AHP) (Yoon, Hwang 1995; Saaty 1988). Each decision maker individually completed his/ her decision matrix $D^{k}=\left[S\left(x_{i j}^{k}\right)\right], k=1,2, \ldots, K$, where $S\left(x_{i j}^{k}\right)$ is an FBS modet like:

$$
S\left(x_{i j}^{k}\right)=\left\{\left(H_{n}, \beta_{n, i j}^{k}\right), n=1,2, \ldots, N\right\},
$$

where: $\beta_{n, i j}^{k}$ represents decision maker $k$ 's assurance that the performance of alternative $A_{i}, i=1,2, \ldots, m$ is at evaluation grade $H_{n}, n=1,2, \ldots, N$ in criterion $X_{j}$, $j=1,2, . ., n$. If $\sum_{n=1}^{N} \beta_{n, i j}^{k}=1$, then the $k$ th decision maker's evaluation over $A_{i}$ alternative in $X_{j}$ criterion is complete and if $\sum_{n=1}^{N} \beta_{n, i j}^{k}<1$, it is incomplete.

\subsection{Constructing the Aggregated Decision Matrix}

As an important step in group decision-making, it is required to aggregate the individual decision matrices in an aggregated one. This aggregation is carried out using the evidential reasoning approach (Yang, Xu 2002; Yang et al. 2006). Since the individual decision matrices $D^{k}$, $k=1,2, \ldots, K$ are fuzzy belief matrices, the aggregated decision matrix $D$ will be a fuzzy belief matrix. It can be expressed as:

$$
D=\left[S\left(x_{i j}\right)\right]=D^{1} \oplus D^{2} \oplus \ldots \oplus D^{K},
$$

where: $S\left(x_{i j}\right)$ represents the aggregated fuzzy belief performance of alternative $A_{i}$ in criterion $X_{j}$. The FBS model $S\left(x_{i j}\right)=\left\{\left(H_{n}, \beta_{n, i j}\right), n=1,2, \ldots, N\right\}$ is constructed based on FBS models $S\left(x_{i j}^{k}\right), k=1,2, \ldots, K$. Wang et al. (2006) proposed an analytic relation between the individual belief degrees $\beta_{n, i j}^{k}, k=1,2, \ldots, K$ with the aggregated belief degree of $\beta_{n, i j}$, as:

$$
\beta_{n}^{i j}=\frac{\mu \cdot\left(a_{1}-a_{2}\right)}{1-\mu \cdot\left(\prod_{k=1}^{K}\left(1-w_{k}^{d}\right)\right)},
$$

where:

$$
\begin{aligned}
& a_{1}=\prod_{k=1}^{K}\left(w_{k}^{d}+1-w_{k}^{d} \sum_{n=1}^{N} \beta_{n, i j}^{k}\right) ; \\
& a_{2}=\prod_{k=1}^{K}\left(1-w_{k}^{d} \sum_{n=1}^{N} \beta_{n, i j}^{k}\right) ; \\
& \mu=\left(\sum_{n=1}^{N} \prod_{k=1}^{K}\left(w_{k}^{d} \beta_{n, i j}^{k}+1-w_{k}^{d} \sum_{n=1}^{N} \beta_{n, i j}^{k}\right)-\right. \\
& \left.(N-1) \prod_{k=1}^{K}\left(1-w_{k}^{d} \sum_{n=1}^{N} \beta_{n, i j}^{k}\right)\right)^{-1} .
\end{aligned}
$$

\subsection{Normalizing the Aggregated Decision Matrix}

If the FBS models are incomplete individually, then obtained aggregated FBS model will be incomplete. Therefore, a normalizing stage is proposed to complete the aggregated FBS models.

In this paper, the normalization is done based on the method of Jiang et al. (2011). Let $s_{i j}=\left\{\left(H_{n}, \beta_{n}^{i j}\right), n=1,2, \ldots, N\right\}$ be an incomplete FBS.

Then, $N$ BS peak points are defined as:

$$
\begin{aligned}
& S P\left(s_{i_{j}}\right)=\left\{\left(H_{n}, \beta_{n}^{m}\right), n=1,2, \ldots, N\right\}, \\
& m=1,2, \ldots, N,
\end{aligned}
$$

with:

$$
\beta_{n}^{m}=\left\{\begin{array}{l}
\beta_{n}+\beta_{H}, m=n ; \\
\beta_{n}, m \neq n,
\end{array}\right.
$$

where: $\beta_{H}=1-\sum_{n=1}^{N} \beta_{n}^{i j}$ is the degree of ignorance for incomplete $s_{i j}$. Then, the center of gravity of FBS model $s_{i j}$ is defined as:

$$
\begin{aligned}
& S C\left(s_{i j}\right)=\frac{\sum_{m=1}^{N} S P\left(s_{i j}\right)}{N}= \\
& \left\{\left(H_{n}, \frac{\sum_{m=1}^{N} \beta_{n}^{m}}{N}\right), n=1,2, \ldots, N\right\} .
\end{aligned}
$$

Then, the complete $S C\left(s_{i j}\right)$ is used instead of incomplete $s_{i j}$ in the pooled decision matrix $X$.

\subsection{Constructing the Fuzzy Belief Distance Matrix}

Considering the decreasing nature of evaluation grades, i.e. $H_{n+1}>H_{n}$, the positive ideal $f_{j}^{+}$and negative ideal $f_{j}^{-}$, FBS models for each criterion $C_{j}, j=1,2, \ldots, n$ are defined as follows:

$$
f_{j}^{+}=\left\{\left(H_{N}, 1\right),\left(H_{N-1}, 0\right), \ldots,\left(H_{1}, 0\right)\right\}
$$

and:

$$
f_{j}^{-}=\left\{\left(H_{N}, 0\right),\left(H_{N-1}, 0\right), \ldots,\left(H_{1}, 1\right)\right\} .
$$

Now, the $S_{i}$ and $R_{i}$ must be found applying Eqs (3) and (4), respectively. To compute these values, the dis- 
tance between FBS models are used. The $S_{i}$ is calculated as follow by considering Eqs (3) and (9):

$$
S_{i}=\sum_{j=1}^{n} w_{j} \frac{d_{B S}\left(f_{j}^{+}, f_{i j}\right)}{d_{B S}\left(f_{j}^{+}, f_{j}^{-}\right)} .
$$

The $R_{i}$ is also defined as:

$$
R_{i}=\max _{j}\left(w_{j} \frac{d_{B S}\left(f_{j}^{+}, f_{i j}\right)}{d_{B S}\left(f_{j}^{+}, f_{j}^{-}\right)}\right) \text {. }
$$

Denominators of both Eqs (19) and (20) are fixed values, since the ideal and negative ideal solutions are similar, in the sense of FBS models, for all the criteria. This fixed denominator is determined as below using Eq. (9) as:

$$
d_{B S}\left(f_{j}^{+}, f_{j}^{-}\right)=\left(\frac{1}{2}\left(B_{j}^{+}-B_{j}^{-}\right) S\left(B_{j}^{+}-B_{j}^{-}\right)^{T}\right)^{1 / 2} .
$$

The following relation is obtained for all values of $j, j=1,2, \ldots, n$ by applying the positive ideal and negative ideal belief degrees in Eqs (17) and (18) in Eq. (21):

$$
d_{B S}\left(f_{j}^{+}, f_{j}^{-}\right)=\left(\frac{1}{2}\left(\left(S_{11}+S_{N N}\right)-\left(S_{N 1}+S_{N N}\right)\right)\right)^{1 / 2} \text {. }
$$

Similarly, $d_{B S}\left(f_{j}^{+}, f_{i j}\right)$ can be found by using Eq. (9) and implying the belief degrees of $f_{j}^{+}$and $f_{i j}$, respectively. By Computing distances for each alternative with each criterion, the following distance matrix can be constructed, where $d_{B S}\left(f_{j}^{+}, f_{i j}\right)$ is illustrated with $d_{i j}^{+}$:

$$
D=\left[\begin{array}{cccc}
d_{11}^{+} & d_{12}^{+} & \cdots & d_{1 n}^{+} \\
d_{21}^{+} & d_{22}^{+} & \cdots & d_{2 n}^{+} \\
\vdots & \vdots & \ddots & \vdots \\
d_{m 1}^{+} & d_{m 2}^{+} & \cdots & d_{m n}^{+}
\end{array}\right] .
$$

Then, the matrix $D$ is normalized by dividing it to $d$, and the normalized distance matrix $N D=\left[n d_{i j}^{+}\right]$, where $n d_{i j}^{+}=\frac{d_{i j}^{+}}{d}, i=1,2, \ldots, m ; j=1,2, \ldots, n$. At the next stage, the weighted normalize fuzzy belief distance matrix $W N D=\left[w n d_{i j}^{+}\right]$is computed by multiplying each element's of matrix $N D$ in its corresponding criterion importance, i.e. $w n d_{i j}^{+}=w_{j} d_{i j}^{+}, i=1,2, \ldots, m ; j=$ $1,2, \ldots, n$.

\subsection{Applying VIKOR Method}

Since the weighted normalized fuzzy belief distance matrix is obtained, now the VIKOR method can be applied to solve the MAGDM problem based on FBSs. First, the values of $S_{i}, i=1,2, \ldots, m$ is computed for alternatives as:

$$
S_{i}=\sum_{j=1}^{n}\left(w n d_{i j}^{+}\right) \text {. }
$$

Then, the values of $R_{i}, i=1,2, \ldots, m$ are calculated:

$$
R_{i}=\max _{j}\left(w n d_{i j}^{+}\right)
$$

$$
\begin{aligned}
& S^{+}=\min _{i} S_{i} \\
& S^{-}=\max _{i} S_{i}
\end{aligned}
$$

and:

$$
\begin{aligned}
& R^{+}=\min _{i} R_{i} ; \\
& R^{-}=\max _{i} R_{i} .
\end{aligned}
$$

Calculate the $Q_{i}$ for $i=1,2, \ldots, m$ using Eq. (5), where the $v$ multiplier is interpreted as in classic VIKOR method. Applying the common values of $S^{+}=R^{+}=0$, and $S^{-}=R^{-}=1$ in Eq. (5), the following relation is obtained:

$$
Q_{i}=v S_{i}+(1-v) R_{i}
$$

Sort the $S, R$, and $Q$ values by ascending order to rank alternatives. There would be 3 lists of ranking illustrated as: $S_{[0]}, R_{[0]}$ and $Q_{[0]}$. After determining these lists, by using step 5 of the VIKOR method in Section 1, the final ranking list will be obtained.

\subsection{Schematic Algorithm}

In this regard, the proposed methodology is illustrated in Fig. 1.

\section{Case Study}

In this regard, the proposed algorithm is applied in a problem of public transportation.

Tehran, the capital of Iran, with a population of more than 14 million, is 17 th largest metropolitan of the world. According to formal reports, more than 18 million intra-urban trips are taken in a working day of Tehran. This magnitude of trips highlighted the importance of intra-urban transformation system. Tehran metro consist of 5 lines and about 90 stations around the city, covers more than 3 million daily trips in Tehran and therefore it plays an important role in Tehran's transformation system. Fig. 2 displays the Tehran's metro map.

The Metro system plays an important role in Tehran's intra-urban transportation system. Considering a uniform traveling rate in its 12-hour working day, a oneminute delay in this system means that 70 person-hour working time of people will be lost. In addition, this delay caused traffic in metro stations, which its handling will be a challenging task. Therefore, it is necessary to find the most important causes of metro delays in Tehran.

To this end, the FMEA approach is used. FMEA determines the most important risks based on Risk Priority Number (RPN) index. RPN is defined as RPN = Occurrence-Sverity-Detection. In fact, the more important risk is one that has higher severity; its occurrence is high, or its detection is more difficult. The classic FMEA has some weaknesses as noted by Vahdani et al. (2014):

- traditional FMEA neglects the relative importance among occurrence, severity, and detection;

- different values of occurrence, severity, and detection may produce similar RPN values;

- the traditional FMEA neglect to human/expert knowledge. 


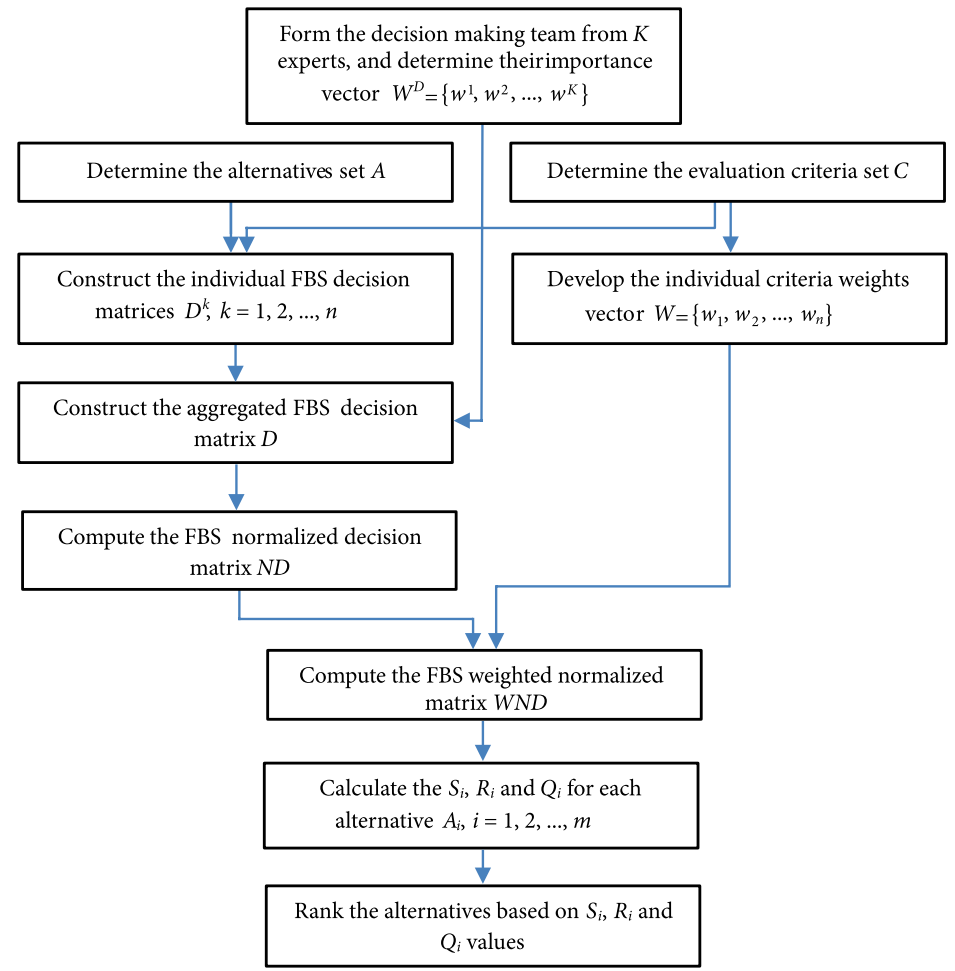

Fig. 1. The flowchart of proposed FBS-VIKOR method for MAGDM

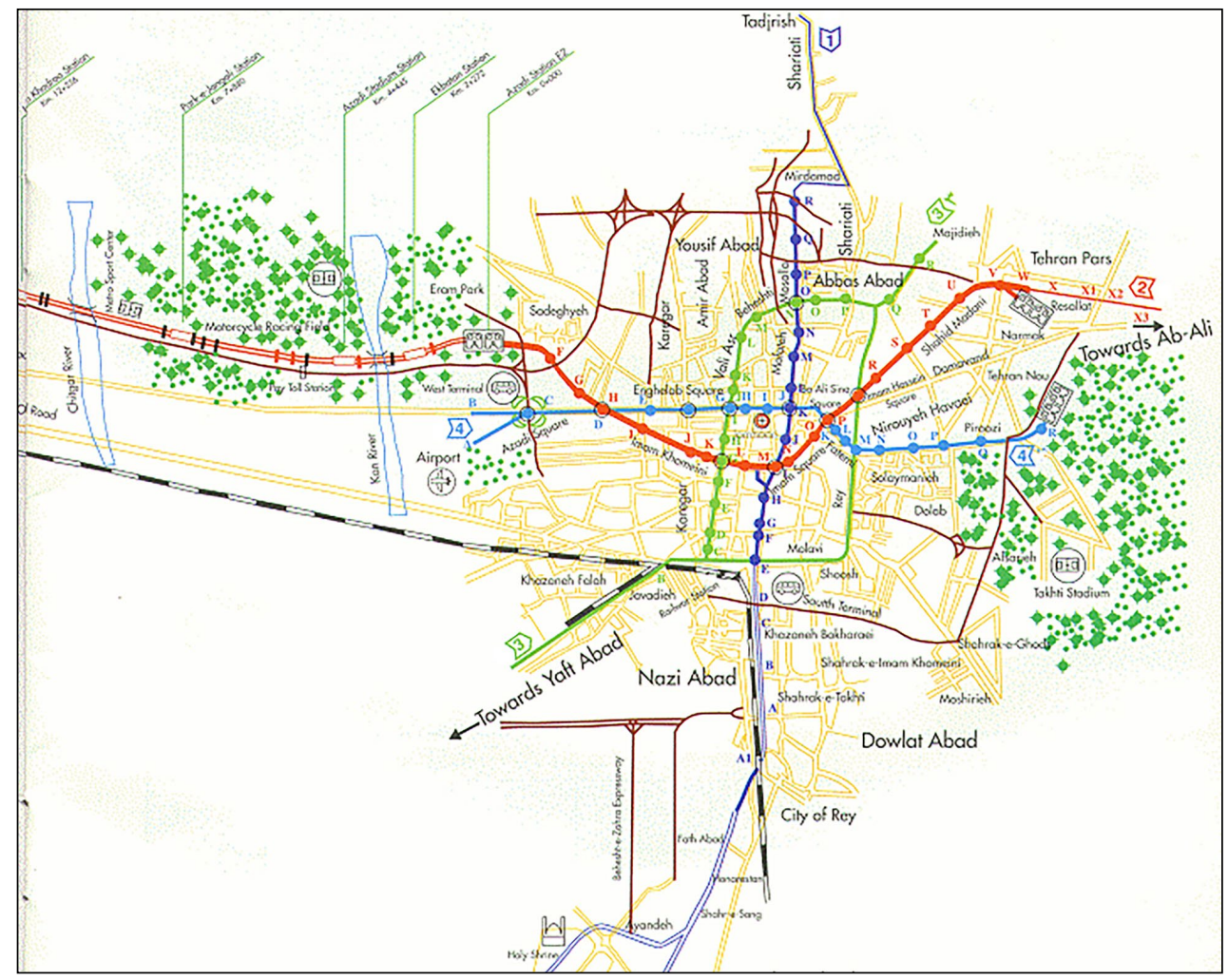

Fig. 2. Tehran metro map

To avoid these weaknesses, the FMEA is combined with FBS based VIKOR method to evaluate the importance of delay causes. In fact, FMEA acts to define the critical criteria for ranking the causes of delay.
A team including 5 experts from Tehran Urban and Suburban Railway Operation Co is formed to find the most important delay causes in Tehran metro system. Considering the previous reports and documents, the team identified 11 factors as the main causes of delays: 
- $A_{1}$ - the transportation system (including the train propulsion, brake system, pneumatic system, wagons door, computer accessories, and technical facilities);

- $A_{2}$ - power systems including the high pressure, distribution channel, transfer lines, etc.;

- $A_{3}$ - facilities including electrical and mechanical facilities;

- $A_{4}-$ control and sign unit involving the switch machine, rail circuit, interlocking, and software and hard ware of traffic control and trains safety system;

- $A_{5}$ - telecommunications;

- $A_{6}$ - line including the railway and switch;

- $A_{7}$ - buildings and stations;

- $A_{8}$ - passengers and other human factors;

- $A_{9}$ - unexpected events such as fire, smoke natural disasters, railway failure, and others;

- $A_{10}$ - leadership including the train leadership, supervisor of traffic control center, and maintenance;

- $A_{11}$ - traffic management in a way to indicate how to utilize the system.

These causes are evaluated by participating experts based on three criteria:

- Severity: occurring this cause, how much severe, based on delay time, will be the delays caused by it?

- Occurrence: how much probable is its occurrence?

- Detection: how much is it possible to detect the considered cause before its occurrence?

Using a group AHP method, prior to constructing individual matrices, the importance of criteria are determined as $w_{\text {severity }}=0.31 ; w_{\text {occurrence }}=0.41 ; w_{\text {detection }}=$ 0.28 and also $W^{D}=(0.2,0.2,0.2,0.2,0.2)$.

An FBS scale is also developed for assessing each delay cause about these criteria, as illustrated in Table 1. Decision makers express their beliefs about how percent they believe that, the severity, occurrence, or detection of a delay cause is hard, moderate, and/or simple.

Considering this FBS scale, individual fuzzy belief decision matrices including the evaluation of experts are shown in Table 2.

The next step is to form an aggregated decision matrix, constructing individual decision matrices, by applying Eqs (12) and (13), and decision makers weight vector $W^{D}$. This matrix $D$ is formed as follows (Table 3 ).

Considering Table 3, except for $S\left(x_{91}\right)$ and $S\left(x_{83}\right)$, all other aggregated FBS models are incomplete, therefore, a normalizing stage is necessary. Applying Eqs (15) and (16), the normalized FBS decision matrix will be obtained as illustrated in Table 4.

Table 1. FBS scale used for delay causes evaluation

\begin{tabular}{|c|l|c|}
\hline Evaluation grade & Linguistic term & Utility \\
\hline$H_{1}$ & severe/hard & $(0.5,0.7,0.9)$ \\
\hline$H_{2}$ & moderate & $(0.3,0.5,0.7)$ \\
\hline$H_{3}$ & weak/simple & $(0.1,0.3,0.5)$ \\
\hline
\end{tabular}

Table 2. FBS individual decision matrices

\begin{tabular}{|c|c|c|c|c|}
\hline $\begin{array}{c}\text { Alter- } \\
\text { natives }\end{array}$ & $\begin{array}{l}\text { Ex- } \\
\text { perts }\end{array}$ & Severity & Occurrence & Detection \\
\hline \multirow{5}{*}{$A_{1}$} & $E_{1}$ & $(0.70,0.20,0.10)$ & $(0.20,0.60,0.20)$ & $(0.30,0.40,0.30)$ \\
\hline & $E_{2}$ & $(0.80,0.05,0.05)$ & $(0.75,0.05,0.05)$ & $(0.10,0.40,0.10)$ \\
\hline & $E_{3}$ & $(0.80,0.20,0.00)$ & $(0.80,0.10,0.10)$ & $(0.80,0.15,0.05)$ \\
\hline & $E_{4}$ & $(0.10,0.65,0.25)$ & $(0.80,0.10,0.05)$ & $(0.15,0.60,0.15)$ \\
\hline & $E_{5}$ & $(0.20,0.30,0.50)$ & $(0.80,0.10,0.10)$ & $(0.60,0.20,0.10)$ \\
\hline \multirow{5}{*}{$A_{2}$} & $E_{1}$ & $(0.60,0.25,0.15)$ & $(0.70,0.15,0.15)$ & $(0.10,0.20,0.60)$ \\
\hline & $E_{2}$ & $(0.00,0.05,0.20)$ & $(0.90,0.00,0.00)$ & $(0.01,0.01,0.10)$ \\
\hline & $E_{3}$ & $(0.90,0.10,0.00)$ & $(0.80,0.10,0.10)$ & $(0.10,0.10,0.80)$ \\
\hline & $E_{4}$ & $(0.85,0.05,0.00)$ & $(0.80,0.05,0.05)$ & $(0.05,0.05,0.30)$ \\
\hline & $E_{5}$ & $(0.40,0.20,0.10)$ & $(0.80,0.10,0.10)$ & $(0.10,0.10,0.80)$ \\
\hline \multirow{5}{*}{$A_{3}$} & $E_{1}$ & $(0.20,0.20,0.50)$ & $(0.10,0.60,0.20)$ & $(0.10,0.10,0.80)$ \\
\hline & $E_{2}$ & $(0.05,0.05,0.50)$ & $(0.90,0.05,0.05)$ & $(0.01,0.01,0.20)$ \\
\hline & $E_{3}$ & $(0.70,0.15,0.15)$ & $(0.70,0.20,0.10)$ & $(0.20,0.20,0.60)$ \\
\hline & $E_{4}$ & $(0.75,0.10,0.15)$ & $(0.10,0.50,0.10)$ & $(0.00,0.10,0.30)$ \\
\hline & $E_{5}$ & $(0.80,0.10,0.10)$ & $(0.30,0.20,0.10)$ & $(0.10,0.10,0.10)$ \\
\hline \multirow{5}{*}{$A_{4}$} & $E_{1}$ & $(0.60,0.15,0.15)$ & $(0.50,0.30,0.20)$ & $(0.75,0.15,0.05)$ \\
\hline & $E_{2}$ & $(0.05,0.50,0.05)$ & $(0.80,0.050,0.05)$ & $(0.05,0.60,0.05)$ \\
\hline & $E_{3}$ & $(0.50,0.40,0.10)$ & $(0.30,0.20,0.50)$ & $(0.30,0.30,0.30)$ \\
\hline & $E_{4}$ & $(0.50,0.20,0.30)$ & $(0.70,0.20,0.10)$ & $(0.8,0.15,0.05)$ \\
\hline & $E_{5}$ & $(0.50,0.30,0.20)$ & $(0.80,0.10,0.10)$ & $(0.7,0.2,0.1)$ \\
\hline \multirow{5}{*}{$A_{5}$} & $E_{1}$ & $(0.80,0.10,0.10)$ & $(0.05,0.10,0.85)$ & $(0.05,0.1,0.85)$ \\
\hline & $E_{2}$ & $(0.90,0.05,0.05)$ & $(0.05,0.05,0.60)$ & $(0.01,0.01,0.20)$ \\
\hline & $E_{3}$ & $(0.80,0.10,0.10)$ & $(0.10,0.10,0.80)$ & $(0.10,0.20,0.70)$ \\
\hline & $E_{4}$ & $(0.8,0.00,0.00)$ & $(0.05,0.05,0.10)$ & $(0.05,0.05,0.3)$ \\
\hline & $E_{5}$ & $(0.60,0.30,0.10)$ & $(0.80,0.10,0.10)$ & $(0.70,0.20,0.10)$ \\
\hline \multirow{5}{*}{$A_{6}$} & $E_{1}$ & $(0.70,0.20,0.10)$ & $(0.15,0.25,0.60)$ & $(0.15,0.25,0.60)$ \\
\hline & $E_{2}$ & $(0.80,0.00,0.00)$ & $(0.80,0.01,0.01)$ & $(0.01,0.01,0.1)$ \\
\hline & $E_{3}$ & $(0.95,0.05,0.00)$ & $(0.50,0.40,0.10)$ & $(0.40,0.30,0.30)$ \\
\hline & $E_{4}$ & $(0.90,0.00,0.10)$ & $(0.80,0.15,0.05)$ & $(0.70,0.20,0.00)$ \\
\hline & $E_{5}$ & $(0.90,0.10,0.00)$ & $(0.90,0.10,0.00)$ & $(0.50,0.20,0.00)$ \\
\hline \multirow{5}{*}{$A_{7}$} & $E_{1}$ & $(0.85,0.05,0.10)$ & $(0.05,0.10,0.85)$ & $(0.05,0.10,0.85)$ \\
\hline & $E_{2}$ & $(0.70,0.10,0.10)$ & $(0.10,0.10,0.60)$ & $(0.40,0.10,0.50)$ \\
\hline & $E_{3}$ & $(0.80,0.15,0.05)$ & $(0.20,0.20,0.60)$ & $(0.30,0.00,0.07)$ \\
\hline & $E_{4}$ & $(0.80,0.10,0.10)$ & $(0.10,0.40,0.10)$ & $(0.10,0.40,0.30)$ \\
\hline & $E_{5}$ & $(0.70,0.10,0.00)$ & $(0.60,0.20,0.00)$ & $(0.30,0.20,0.10)$ \\
\hline \multirow{5}{*}{$A_{8}$} & $E_{1}$ & $(0.60,0.15,0.25)$ & $(0.70,0.15,0.15)$ & $(0.70,0.15,0.15)$ \\
\hline & $E_{2}$ & $(0.80,0.05,0.05)$ & $(0.05,0.50,0.05)$ & $(0.95,0.03,0.02)$ \\
\hline & $E_{3}$ & $(0.95,0.00,0.05)$ & $(0.60,0.30,0.10)$ & $(0.70,0.20,0.10)$ \\
\hline & $E_{4}$ & $(0.85,0.05,0.10)$ & $(0.90,0.05,0.05)$ & $(0.95,0.05,0.00)$ \\
\hline & $E_{5}$ & $(0.50,0.30,0.20)$ & $(0.90,0.10,0.00)$ & $(0.90,0.10,0.00)$ \\
\hline \multirow{5}{*}{$A_{9}$} & $E_{1}$ & $(0.10,0.10,0.80)$ & $(0.80,0.20,0.00)$ & $(0.00,0.05,0.95)$ \\
\hline & $E_{2}$ & $(0.02,0.02,0.30)$ & $(0.90,0.05,0.05)$ & $(0.00,0.02,0.10)$ \\
\hline & $E_{3}$ & $(0.20,0.10,0.70)$ & $(0.97,0.02,0.01)$ & $(0.15,0.15,0.70)$ \\
\hline & $E_{4}$ & $(0.70,0.30,0.00)$ & $(0.85,0.10,0.05)$ & $(0.05,0.05,0.20)$ \\
\hline & $E_{5}$ & $(0.10,0.20,0.70)$ & $(1.00,0.00,0.00)$ & $(0.10,0.20,0.40)$ \\
\hline \multirow{5}{*}{$A_{10}$} & $E_{1}$ & $(0.40,0.15,0.45)$ & $(0.60,0.20,0.10)$ & $(0.40,0.20,0.20)$ \\
\hline & $E_{2}$ & $(0.80,0.05,0.05)$ & $(0.00,0.05,0.30)$ & $(0.05,0.05,0.30)$ \\
\hline & $E_{3}$ & $(0.80,0.10,0.10)$ & $(0.30,0.00,0.70)$ & $(0.20,0.20,0.60)$ \\
\hline & $E_{4}$ & $(0.60,0.15,0.15)$ & $(0.20,0.40,0.10)$ & $(0.50,0.30,0.20)$ \\
\hline & $E_{5}$ & $(0.00,0.20,0.70)$ & $(1.00,0.00,0.00)$ & $(0.60,0.20,0.20)$ \\
\hline \multirow{5}{*}{$A_{11}$} & $E_{1}$ & $(0.50,0.30,0.20)$ & $(0.70,0.20,0.10)$ & $(0.10,0.10,0.80)$ \\
\hline & $E_{2}$ & $(0.70,0.15,0.05)$ & $(0.70,0.15,0.15)$ & $(0.10,0.25,0.55)$ \\
\hline & $E_{3}$ & $(0.90,0.10,0.00)$ & $(0.40,0.50,0.10)$ & $(0.30,0.00,0.70)$ \\
\hline & $E_{4}$ & $(0.10,0.10,0.30)$ & $(0.85,0.10,0.05)$ & $(0.40,0.10,0.30)$ \\
\hline & $E_{5}$ & $(0.10,0.10,0.80)$ & $(0.40,0.20,0.10)$ & $(0.30,0.20,0.00)$ \\
\hline
\end{tabular}


Table 3. Aggregated decision matrix

\begin{tabular}{|c|c|c|c|}
\hline $\begin{array}{c}\text { Alter- } \\
\text { natives }\end{array}$ & Severity & Occurrence & Detection \\
\hline$A_{1}$ & $(0.5525,0.2679,0.1631)$ & $(0.7252,0.1612,0.0830)$ & $(0.4110,0.3597,0.1318)$ \\
\hline$A_{2}$ & $(0.6284,0.1213,0.0778)$ & $(0.8519,0.0600,0.0600)$ & $(0.0691 .0 .0890,0.6086)$ \\
\hline$A_{3}$ & $(0.5450,0.1097,0.2658)$ & $(0.4538,0.3133,0.1032)$ & $(0.0866,0.1070,0.4815)$ \\
\hline$A_{4}$ & $(0.4615,0.3073,0.1510)$ & $(0.6704,0.1483,0.1655)$ & $(0.5654,0.2650,0.0976)$ \\
\hline$A_{5}$ & $(0.8340,0.0846,0.0533)$ & $(0.2047,0.0756,0.5511)$ & $(0.1848,0.1137,0.4875)$ \\
\hline$A_{6}$ & $(0.8948,0.0524,0.0283)$ & $(0.6827,0.1608,0.1284)$ & $(0.3899,0.2020,0.2062)$ \\
\hline$A_{7}$ & $(0.8269,0.0772,0.0536)$ & $(0.2036,0.1940,0.4712)$ & $(0.2205,0.1447,0.5391)$ \\
\hline$A_{8}$ & $(0.7955,0.0862,0.1036)$ & $(0.6914,0.1902,0.0585)$ & $(0.8844,0.0773,0.0382)$ \\
\hline$A_{9}$ & $(0.2159,0.1366,0.5461)$ & $(0.9350,0.0503,0.0147)$ & $(0.0593,0.0939,0.5615)$ \\
\hline$A_{10}$ & $(0.5573,0.1173,0.2762)$ & $(0.4704,0.1219,0.2391)$ & $(0.3745,0.1896,0.3083)$ \\
\hline$A_{11}$ & $(0.5002,0.1425,0.2611)$ & $(0.6635,0.2061,0.0847)$ & $(0.2328,0.1190,0.5211)$ \\
\hline
\end{tabular}

Table 4. Normalized FBS decision matrix

\begin{tabular}{|c|c|c|c|}
\hline $\begin{array}{c}\text { Alter- } \\
\text { natives }\end{array}$ & Severity & Occurrence & Detection \\
\hline$A_{1}$ & $(0.5580,0.2734,0.1686)$ & $(0.7354,0.1714,0.0932)$ & $(0.4435,0.3922,0.1643)$ \\
\hline$A_{2}$ & $(0.6860,0.1788,0.1353)$ & $(0.8613,0.0694,0.0694)$ & $(0.1469 .0 .1668,0.6864)$ \\
\hline$A_{3}$ & $(0.5715,0.1362,0.2923)$ & $(0.4970,0.3565,0.1464)$ & $(0.1949,0.2153,0.5898)$ \\
\hline$A_{4}$ & $(0.4882,0.3340,0.1777)$ & $(0.6757,0.1536,0.1707)$ & $(0.5894,0.2890,0.1216)$ \\
\hline$A_{5}$ & $(0.8434,0.0940,0.0626)$ & $(0.2609,0.1318,0.6073)$ & $(0.2561,0.1850,0.5589)$ \\
\hline$A_{6}$ & $(0.9036,0.0591,0.0372)$ & $(0.6921,0.1701,0.1378)$ & $(0.4572,0.2693,0.2735)$ \\
\hline$A_{7}$ & $(0.8410,0.0913,0.0677)$ & $(0.2474,0.2377,0.5149)$ & $(0.2524,0.1766,0.5710)$ \\
\hline$A_{8}$ & $(0.8004,0.0911,0.1085)$ & $(0.7114,0.2101,0.0785)$ & $(0.8844,0.0773,0.0382)$ \\
\hline$A_{9}$ & $(0.2497,0.1704,0.5799)$ & $(0.9350,0.0503,0.0147)$ & $(0.1544,0.189,0.6566)$ \\
\hline$A_{10}$ & $(0.5736,0.1337,0.2926)$ & $(0.5266,0.1781,0.2953)$ & $(0.4170,0.2321,0.3508)$ \\
\hline$A_{11}$ & $(0.5323,0.1746,0.2931)$ & $(0.6787,0.2214,0.1000)$ & $(0.2752,0.1614,0.5635)$ \\
\hline
\end{tabular}

The normalized FBS decision matrix is used to compute the distance matrix $D$ by Eq. (23). Considering the fuzzy utilities of evaluation grades, the similarity matrix is first calculated:

$$
S=\left[\begin{array}{ccc}
1 & 0.8 & 0.6 \\
0.8 & 1 & 0.8 \\
0.6 & 0.8 & 1
\end{array}\right] .
$$
ing $S$ :

The distance matrix $D$ is computed as below by us-

$$
D=\left[\begin{array}{lll}
0.2116 & 0.1255 & 0.2595 \\
0.1529 & 0.0694 & 0.4897 \\
0.2320 & 0.2343 & 0.4463 \\
0.2423 & 0.1639 & 0.1915 \\
0.0754 & 0.4278 & 0.4161 \\
0.0462 & 0.1509 & 0.2718 \\
0.0773 & 0.4078 & 0.4207 \\
0.1016 & 0.1338 & 0.0544 \\
0.4241 & 0.0298 & 0.4788 \\
0.2313 & 0.2495 & 0.3040 \\
0.2469 & 0.1505 & 0.4106
\end{array}\right] .
$$

Considering $d_{B S}\left(f_{j}^{+}, f_{j}^{-}\right)=0.6325$, the normalized distance matrix ND is found by dividing elements of $D$ into $d_{B} S\left(f_{j}^{+}, f_{j}^{-}\right)$. The obtained matrix is formed as:

$$
N D=\left[\begin{array}{lll}
0.3345 & 0.1984 & 0.4103 \\
0.2418 & 0.1097 & 0.7743 \\
0.3668 & 0.3704 & 0.7057 \\
0.3831 & 0.2592 & 0.3028 \\
0.1192 & 0.6764 & 0.6579 \\
0.0731 & 0.2385 & 0.4298 \\
0.1222 & 0.6448 & 0.6652 \\
0.1606 & 0.2115 & 0.0861 \\
0.6706 & 0.0471 & 0.7570 \\
0.3657 & 0.3945 & 0.4811 \\
0.3903 & 0.2379 & 0.6492
\end{array}\right] .
$$

Constructing the matrix $N D$, it remains to find the weighted normalized decision matrix $W N D$, by multiplying each element of $N D$ at its associated attributes weight. Then, the $S_{i}$ and $R_{i}$ values for each alternative is determined by Eqs (23) and (24). Defining $S^{+}=$ $R^{+}=0$, and $S^{-}=R^{-}=1$, the $Q_{i}, i=1,2, \ldots, 11$ values are computed using Eq. (27), for different values of $v$. 
Table 5. $S_{i}, R_{i}$ and $Q_{i}$ values for different $v$

\begin{tabular}{|c|c|c|c|c|c|c|c|c|c|c|c|c|c|}
\hline \multirow{2}{*}{ Alternative } & \multirow{2}{*}{$\mathrm{S}_{\mathrm{i}}$} & \multirow{2}{*}{$R_{i}$} & \multicolumn{11}{|c|}{$Q_{i}$} \\
\hline & & & 0 & 0.1 & 0.2 & 0.3 & 0.4 & 0.5 & 0.6 & 0.7 & 0.8 & 0.9 & 1 \\
\hline$A_{1}$ & 0.2999 & 0.1149 & 2 & 3 & 3 & 3 & 3 & 3 & 3 & 3 & 3 & 3 & 3 \\
\hline$A_{2}$ & 0.3367 & 0.2168 & 9 & 8 & 7 & 7 & 6 & 5 & 5 & 5 & 5 & 5 & 5 \\
\hline$A_{3}$ & 0.4632 & 0.1976 & 7 & 7 & 8 & 8 & 9 & 9 & 9 & 9 & 9 & 9 & 9 \\
\hline$A_{4}$ & 0.3098 & 0.1188 & 3 & 4 & 4 & 4 & 4 & 4 & 4 & 4 & 4 & 4 & 4 \\
\hline$A_{5}$ & 0.4985 & 0.2773 & 11 & 11 & 11 & 11 & 11 & 11 & 11 & 11 & 11 & 11 & 11 \\
\hline$A_{6}$ & 0.2408 & 0.1203 & 4 & 2 & 2 & 2 & 2 & 2 & 2 & 2 & 2 & 2 & 2 \\
\hline$A_{7}$ & 0.4885 & 0.2644 & 10 & 10 & 10 & 10 & 10 & 10 & 10 & 10 & 10 & 10 & 10 \\
\hline$A_{8}$ & 0.1606 & 0.0867 & 1 & 1 & 1 & 1 & 1 & 1 & 1 & 1 & 1 & 1 & 1 \\
\hline$A_{9}$ & 0.4392 & 0.2120 & 8 & 9 & 9 & 9 & 8 & 8 & 8 & 8 & 8 & 8 & 8 \\
\hline$A_{10}$ & 0.4098 & 0.1618 & 5 & 5 & 5 & 5 & 5 & 6 & 6 & 7 & 7 & 7 & 7 \\
\hline$A_{11}$ & 0.4003 & 0.1818 & 6 & 6 & 6 & 6 & 7 & 7 & 7 & 6 & 6 & 6 & 6 \\
\hline
\end{tabular}

These values are computed and ranked at Table 5. According to this table, there are not any paradoxical ranking in different values of $v$ and just some minor differences occur for these values. Using the mean of ranks as the aggregating methods (Yoon, Hwang 1995), the final ranking of delay causes is presented in Table 6 , in the FBS-VIKOR column.

According to the results of Table 6, the three most important delay causes include passengers and other human factors, line including the railway and switch, the transportation system (including the train propulsion, brake system, pneumatic system, wagons door, computer accessories, and technical facilities). Therefore, some training and informative programs should be planned to resolve human related issues. In addition, it seems necessary to design and deploy an improved maintenance program for solving the problems related to line and transportation system. In this table, the results obtained by solving the problem using FBS-TOPSIS method of Jiang et al. (2011) and Vahdani et al. (2014) is also presented. As it is clear from Table 5 results, except for 6 th and 7 th ranks, all other alternatives obtained similar ranks in both methods. The Spearman's rank correlation between both methods is about 0.97 .

Table 6. Final ranking and comparison

\begin{tabular}{|c|c|c|}
\hline \multirow{2}{*}{ Alternatives } & \multicolumn{2}{|c|}{ Rank } \\
\cline { 2 - 3 } & FBS-VIKOR & FBS-TOPSIS \\
\hline$A_{1}$ & 3 & 3 \\
\hline$A_{2}$ & 6 & 5 \\
\hline$A_{3}$ & 9 & 9 \\
\hline$A_{4}$ & 4 & 4 \\
\hline$A_{5}$ & 11 & 11 \\
\hline$A_{6}$ & 2 & 2 \\
\hline$A_{7}$ & 10 & 10 \\
\hline$A_{8}$ & 1 & 1 \\
\hline$A_{9}$ & 8 & 8 \\
\hline$A_{10}$ & 5 & 7 \\
\hline$A_{11}$ & 7 & 6 \\
\hline
\end{tabular}

\section{Conclusions}

Multi attribute group decision-making problems are a set of widely used procedures to choose the best alternative or to rank a set of alternatives based on a set of different and usually contrasting attributes. Vincke (1992) believed that this family of problems is usually difficult to solve. This difficulty is a result of nonexistence of a global optimal solution for these problems. On the other hand, often decision makers do not have complete information regard to required information for decision-making problems. This feature of uncertainty is formulated under different frameworks. One of the recent and strength frameworks of dealing with uncertainty is FBS. This well-defined approach constituted of an evaluation grade that is represented as fuzzy grades along with a belief degree assigned to each evaluation grade. In FBS, decision makers most specify their belief degree about each alternative performance regard to each attribute in every evaluation grade. Combination of fuzzy set theory and the evidence combination rule of the Dempster-Shafer theory made FBS as a powerful way of portraying human uncertainty.

In this paper, the VIKOR as an accepted MAGDM method is extended under the condition that decision makers express their judgments about alternatives performance regard to attributes in the form of FBS models. Using evidential reasoning approach, the individual FBS decision matrices of decision makers are aggregated in a single one. Then, the center of gravity method is applied to normalize the aggregated decision matrix. Distances of alternatives from these ideals are computed following the VIKOR method procedure by defining the positive ideal and negative ideal FBS models.

The main advantages of the proposed method can be stated as:

- providing a flexible framework for experts to state their judgment in a linguistic evaluation grade along with belief degrees;

- provide a method of group decision-making by aggregating different experts' opinion by considering their relative importance and weights;

- obtain a consensus based result for the decision- 
making process which can be applied in different transportation decision-making problems and other areas.

An application of the proposed method is shown in ranking the causes of delay in Tehran metro system. Ranking criteria are defined according to FMEA approach. Then, five experts' opinion are gathered in the form of FBS model and the proposed FBS-based VIKOR method is applied. The obtained results showed that the most important delay causes are human related issues and line and transportation system. Finding the most important delay causes, a set of corrective actions can be designed to resolve the undesirable consequences. Comparison of the results with a previously proposed method represented a high consistency among the methods as a strengthening fact about the proposed FBS-VIKOR method. Future researches in this area can be directed toward extension of other decision-making methods, include outranking methods, under FBS information. In addition, researchers can concentrate on extension of mathematical operations of FBSs.

\section{References}

Atanassov, K. T. 1986 Intuitionistic fuzzy sets, Fuzzy Sets and Systems 20(1): 87-96.

http://dx.doi.org/10.1016/S0165-0114(86)80034-3

Atanassov, K.; Gargov, G. 1989. Interval valued intuitionistic fuzzy sets, Fuzzy Sets and Systems 31(3): 343-349. http://dx.doi.org/10.1016/0165-0114(89)90205-4

Bagočius, V.; Zavadskas, E. K.; Turskis, Z. 2014. Selecting a location for a liquefied natural gas terminal in the Eastern Baltic Sea, Transport 29(1): 69-74. http://dx.doi.org/10.3846/16484142.2014.897996

Banister, D. 1996. Energy, quality of life and the environment: the role of transport, Transport Reviews 16(1): 23-35. http://dx.doi.org/10.1080/01441649608716931

Baležentis, T.; Zeng, S. 2013. Group multi-criteria decision making based upon interval-valued fuzzy numbers: an extension of the MULTIMOORA method, Expert Systems with Applications 40(2): 543-550.

http://dx.doi.org/10.1016/j.eswa.2012.07.066

Bellman, R. E.; Zadeh, L. A. 1970. Decision-making in a fuzzy environment, Management Science 17(4): B141-B164. http://dx.doi.org/10.1287/mnsc.17.4.B141

Chen, T.-Y. 2015. The inclusion-based TOPSIS method with interval-valued intuitionistic fuzzy sets for multiple criteria group decision making, Applied Soft Computing 26: 57-73. http://dx.doi.org/10.1016/j.asoc.2014.09.015

Chen, T.-Y. 2013. A signed-distance-based approach to importance assessment and multi-criteria group decision analysis based on interval type-2 fuzzy set, Knowledge and Information Systems 35(1): 193-231.

http://dx.doi.org/10.1007/s10115-012-0497-6

Devi, K. 2011. Extension of VIKOR method in intuitionistic fuzzy environment for robot selection, Expert Systems with Applications 38(11): 14163-14168.

http://dx.doi.org/10.1016/j.eswa.2011.04.227

Dubois, D.; Prade, H. 1982. A class of fuzzy measures based on triangular norms: a general framework for the combination of uncertain information, International Journal of General Systems 8(1): 43-61.

http://dx.doi.org/10.1080/03081078208934833
Elevli, B. 2014. Logistics freight center locations decision by using fuzzy-PROMETHEE, Transport 29(4): 412-418. http://dx.doi.org/10.3846/16484142.2014.983966

Grattan-Guinness, I. 1976. Fuzzy membership mapped onto intervals and many-valued quantities, Mathematical Logic Quarterly 22(1): 149-160.

http://dx.doi.org/10.1002/malq.19760220120

Gifford, R.; Steg, L. 2007. The impact of automobile traffic on quality of life, in T. Gärling, L. Steg (Eds.). Threats from Car Traffic to the Quality of Urban Life: Problems, Causes, Solutions, 33-52.

Hashemi, S. S.; Razavi Hajiagha, S. H.; Zavadskas, E. K.; Amoozad Mahdiraji, H. 2016. Multicriteria group decision making with ELECTRE III method based on interval-valued intuitionistic fuzzy information, Applied Mathematical Modelling 40(2): 1554-1564

http://dx.doi.org/10.1016/j.apm.2015.08.011

Inuiguchi, M.; Ramík, J. 2000. Possibilistic linear programming: a brief review of fuzzy mathematical programming and a comparison with stochastic programming in portfolio selection problem, Fuzzy Sets and Systems 111(1): 3-28. http://dx.doi.org/10.1016/S0165-0114(98)00449-7

Jiang, J.; Chen, Y.-W.; Chen, Y.-W.; Yang, K.-W. 2011. TOPSIS with fuzzy belief structure for group belief multiple criteria decision making, Expert Systems with Applications 38(8): 9400-9406. http://dx.doi.org/10.1016/j.eswa.2011.01.128

Klir, G. J. 1987. Where do we stand on measures of uncertainty, ambiguity, fuzziness, and the like?, Fuzzy Sets and Systems 24(2): 141-160. http://dx.doi.org/10.1016/0165-0114(87)90087-X

Liang, Q.; Mendel, J. M. 2000. Interval type-2 fuzzy logic systems: theory and design, IEEE Transactions on Fuzzy Systems 8(5): 535-550. http://dx.doi.org/10.1109/91.873577

Liu, S.; Lin, Y. 2006. Grey Information: Theory and Practical Applications. Springer. $585 \mathrm{p}$.

Maldonado, Y.; Castillo, O.; Melin, P. 2014. A multi-objective optimization of type-2 fuzzy control speed in FPGAs, Applied Soft Computing 24: 1167-1174. http://dx.doi.org/10.1016/j.asoc.2014.04.041

Martine, G. 2005. Population/development/environment trends in a globalized context: challenges for the 21 st century, Genus 61(3-4): 247-277.

Opricovic, S. 2011. Fuzzy VIKOR with an application to water resources planning, Expert Systems with Applications 38(10): 12983-12990.

http://dx.doi.org/10.1016/j.eswa.2011.04.097

Opricovic, S. 2007. A fuzzy compromise solution for multicriteria problems, International Journal of Uncertainty, Fuzziness and Knowledge-Based Systems 15(3): 363-380. http://dx.doi.org/10.1142/S0218488507004728

Opricovic, S. 1998. Višekriterijumska optimizacija sistema u građevinarstvu. Građevinski fakultet, Beograd. 302 s. (in Serbian).

Opricovic, S.; Tzeng, G.-H. 2004. Compromise solution by MCDM methods: A comparative analysis of VIKOR and TOPSIS, European Journal of Operational Research 156(2): 445-455. http://dx.doi.org/10.1016/S0377-2217(03)00020-1

Park, J. H.; Cho, H. J.; Kwun, Y. C. 2011. Extension of the VIKOR method for group decision making with intervalvalued intuitionistic fuzzy information, Fuzzy Optimization and Decision Making 10(3): 233-253. http://dx.doi.org/10.1007/s10700-011-9102-9

Razavi Hajiagha, S. H.; Amoozad Mahdiraji, H.; Hashemi, S. S.; Zavadskas, E. K. 2015. Evolving a linear programming technique for MAGDM problems with interval valued in- 
tuitionistic fuzzy information, Expert Systems with Applications 42(23): 9318-9325.

http://dx.doi.org/10.1016/j.eswa.2015.07.067

Razavi Hajiagha, S. H.; Amoozad Mahdiraji, H.; Zavadskas, E. K.; Hashemi, S. S. 2014. Fuzzy multi-objective linear programming based on compromise VIKOR method, International Journal of Information Technology \& Decision Making 13(4): 679-698.

http://dx.doi.org/10.1142/S0219622014500667

Razavi Hajiagha, S. H.; Hashemi, S. S.; Zavadskas, E. K. 2013. A complex proportional assessment method for group decision making in an interval-valued intuitionistic fuzzy environment, Technological and Economic Development of Economy 19(1): 22-37.

http://dx.doi.org/10.3846/20294913.2012.762953

Saaty, T. L. 1988. What is the analytic hierarchy process?, in G. Mitra, H. J. Greenberg, F. A. Lootsma, M. J. Rijkaert, H. J. Zimmermann (Eds.). Mathematical Models for Decision Support, 109-121.

http://dx.doi.org/10.1007/978-3-642-83555-1_5

Šateikienė, D.; Janutėnienė, J.; Bogdevičius, M.; Mickevičienè, R. 2015. Analysis into the selection of a ballast water treatment system, Transport 30(2): 145-151.

http://dx.doi.org/10.3846/16484142.2015.1045025

Simon, H. A. 1977. The logic of heuristic decision making, Models of Discovery 54: 154-175.

http://dx.doi.org/10.1007/978-94-010-9521-1_10

Tan, C.; Ma, B.; Wu, D. D.; Chen, X. 2014. Multi-criteria decision making methods based on interval-valued intuitionistic fuzzy sets, International Journal of Uncertainty, Fuzziness and Knowledge-Based Systems 22(3): 469-488. http://dx.doi.org/10.1142/S0218488514500238

Tzeng, G.-H.; Huang, J.-H. 2011. Multiple Attribute Decision Making: Methods and Applications. Chapman and Hall/ CRC. $352 \mathrm{p}$.

UN. 2015. World Urbanization Prospect: The 2014 Revision. United Nations (UN), Department of Economic and Social Affairs, Population Division. ST/ESA/SER.A/366. 517 p. Available from Internet: http://esa.un.org/unpd/wup

UN. 2010. Shanghai Manual: A Guide for Sustainable Urban Development in the 21st Century. United Nations (UN). Shanghai 2010 World Exposition Executive Committee 320 p. Available from Internet: https://sustainabledevelopment.un.org/index.php?page $=$ view\&type $=400 \& n r=633 \& \mathrm{~m}$ $\mathrm{enu}=1515$

Vahdani, B.; Hadipour, H.; Salehi Sadaghiani, J.; Amiri, M. 2010. Extension of VIKOR method based on intervalvalued fuzzy sets, The International Journal of Advanced Manufacturing Technology 47(9-12): 1231-1239. http://dx.doi.org/10.1007/s00170-009-2241-2

Vahdani, B.; Salimi, M.; Charkhchian, M. 2014. A new FMEA method by integrating fuzzy belief structure and TOPSIS to improve risk evaluation process, The International Journal of Advanced Manufacturing Technology 77(1-4): 357-368. http://dx.doi.org/10.1007/s00170-014-6466-3

Vincke, P. 1992. Multicriteria Decision-Aid. Wiley. 174 p.

Wang, W.; Liu, X.; Qin, Y. 2012. Multi-attribute group decision making models under interval type-2 fuzzy environment, Knowledge-Based Systems 30: 121-128. http://dx.doi.org/10.1016/j.knosys.2012.01.005

Wang, Y.-M.; Yang, J.-B.; Xu, D.-L. 2006. Environmental impact assessment using the evidential reasoning approach, European Journal of Operational Research 174(3): 18851913. http://dx.doi.org/10.1016/j.ejor.2004.09.059
Yang, J.-B.; Sen, P. 1994. A general multi-level evaluation process for hybrid MADM with uncertainty, IEEE Transactions on Systems, Man and Cybernetics 24(10): 1458-1473.

http://dx.doi.org/10.1109/21.310529

Yang, J.-B.; Singh, M. G. 1994. An evidential reasoning approach for multiple-attribute decision making with uncertainty, IEEE Transactions on Systems, Man and Cybernetics 24(1): 1-18. http://dx.doi.org/10.1109/21.259681

Yang, J. B.; Wang, Y. M.; Xu, D. L.; Chin, K. S. 2006. The evidential reasoning approach for MADA under both probabilistic and fuzzy uncertainties, European Journal of Operational Research 171(1): 309-343. http://dx.doi.org/10.1016/j.ejor.2004.09.017

Yang, J.-B.; Xu, D.-L. 2002. On the evidential reasoning algorithm for multiple attribute decision analysis under uncertainty, IEEE Transactions on Systems, Man and Cybernetics, Part A: Systems and Humans 32(3): 289-304. http://dx.doi.org/10.1109/TSMCA.2002.802746

Yoon, K. P.; Hwang, C.-L. 1995. Multiple Attribute Decision Making: an Introduction. SAGE Publications.

Yu, P. L. 1990. Forming Winning Strategies: an Integrated Theory of Habitual Domains. Springer. 392 p. http://dx.doi.org/10.1007/978-3-642-61295-4

Zadeh, L. A. 1975. The concept of a linguistic variable and its application to approximate reasoning - I, Information Sciences 8(3): 199-249. http://dx.doi.org/10.1016/00200255(75)90036-5

Zadeh, L. A. 1965. Fuzzy sets, Information and Control 8(3): 338 353. http://dx.doi.org/10.1016/S0019-9958(65)90241-X

Zavadskas, E. K.; Antuchevičienè, J.; Razavi Hajiagha, S. H.; Hashemi, S. S. 2015. The interval-valued intuitionistic fuzzy MULTIMOORA method for group decision making in engineering, Mathematical Problems in Engineering 2015: 1-13. http://dx.doi.org/10.1155/2015/560690

Zavadskas, E. K.; Antuchevičienè, J.; Razavi Hajiagha, S. H.; Hashemi, S. S. 2014. Extension of weighted aggregated sum product assessment with interval-valued intuitionistic fuzzy numbers (WASPAS-IVIF), Applied Soft Computing 24: 1013-1021. http://dx.doi.org/10.1016/j.asoc.2014.08.031

Zhou, L.; Tao, Z.; Chen, H.; Liu, J. 2013. Some ICOWA operators and their applications to group decision making with interval fuzzy preference relations, International Journal of Uncertainty, Fuzziness and Knowledge-Based Systems 21(4): 579-601. http://dx.doi.org/10.1142/S0218488513500281

Zimmerman, H.-J. 1987. Fuzzy Sets, Decision Making, and Expert Systems. Kluwer Academic Publishers. 336 p. 